\title{
DETERMINATION AND VALIDATION OF RP-HPLC METHOD FOR THE ESTIMATION OF MIRABEGRON IN TABLET DOSAGE FORM
}

\author{
B. MOUNIKA*, L. SRIKANTH, A. VENKATESHA \\ SVS Group of Institutions, School of Pharmacy, Hanamkonda Warangal, Telangana 506015 \\ Email: monasri289@gmail.com
}

Received: 23 May 2017, Revised and Accepted: 22 Jul 2017

\begin{abstract}
Objective: A reversed phase liquid chromatography was determined and validated for the estimation of Mirabegron in tablet dosage form.

Methods: The validation study of RP-HPLC showed a simple, rapid, accurate, precise, reproducible results by using a stationary phase: Waters Acquity HSS T-3 $\mathrm{C}_{18}(100 \times 2.1 \mathrm{~mm}, 1.7 \mathrm{~m}$ and Mobile Phase-Potassium di-hydrogen phosphate: acetone in the ratio (40:60 v/v) at PH $6.0 \pm 0.02$. Detection is carried out at $243 \mathrm{~nm}$ using UV detector.

Results: The total chromatographic analysis time per sample was about 6 min with Mirabegron eluting at a retention time of 2.754. Tailing factor obtained from the standard injection is 1.6 . Theoretical Plates obtained from the standard injection is 2736.7 . The flow rate is 1 ml/min and linearity in the concentration range of $30-70 \mu \mathrm{g} / \mathrm{ml}\left(\mathrm{R}^{2}=0.999\right)$. The precision was $0.4 \%$ the intermediate precision was $0.08 \%$. The deliberately varied chromatographic conditions in the concentration range for the evaluation of robustness is $10-50 \mu \mathrm{g} / \mathrm{ml}$, (n=3). The limit of detection (LOD) and limit of quantitation (LOQ) for Mirabegron were $0.01 \mu \mathrm{g} / \mathrm{ml}$ and $0.05 \mu \mathrm{g} / \mathrm{ml}$ respectively. The \% recovery is $99.8 \%$ with \% R. SD of 0.09 . The results proved that the optimized HPLC method fulfills these requirements within the ICH accepted limits.
\end{abstract}

Conclusion: The high recovery and low relative standard deviation confirm the suitability of the proposed method for the determination of Mirabegron in tablet dosage form.

Keywords: Reverse phase high-performance liquid chromatography, Mirabegron, Potassium dihydrogen phosphate, Acetone, UV detector

(C) 2017 The Authors. Published by Innovare Academic Sciences Pvt Ltd. This is an open access article under the CC BY license (http://creativecommons.org/licenses/by/4.0/) DOI: http://dx.doi.org/10.22159/ijcpr.2017v9i5.22158

\section{INTRODUCTION}

Drug discovery process has been shortened owing to the introduction of technology like high throughput screening, CAD etc. The development of new chemical entities (NCEs) is comprised of two major activities: drug discovery and drug development. The goal of the drug discovery program is to investigate a plethora of compounds employing fast screening approaches, leading to the generation of lead compounds and then narrowing the selection through targeted synthesis and selective screening (lead optimization). There is a time lag from the date of introduction of a drug into the market to the date of its inclusion in pharmacopoeias. This happens because of the possible uncertainties in the continuous and wider usage of these drugs, reports of new toxicities (resulting in their withdrawal from the market), development of patient resistance and introduction of better drugs by competitors. Under these conditions, standards and analytical procedures for these drugs may not be available in the pharmacopoeias. It becomes necessary, therefore to develop newer analytical methods for such drugs [1-2]. Analytical techniques play an important role in maintaining and assuring the quality of drugs and are critical components of $\mathrm{Q}$. A/Q. C The discipline of analytical chemistry consists of:

- Qualitative analysis

- Quantitative analysis

Qualitative analysis yields information about the identity of atomic or molecular species or the functional groups with the sample. Quantitative analysis, in contrast, provides numerical information as to the relative amount of one or more of these components. Therefore qualitative information is required before a quantitative analysis can be undertaken. A separation step is usually unnecessary part of both a qualitative and quantitative analysis [3-7].

Chromatography is a physical separation method in which the components of a mixture are separated by differences in their distribution between two phases, one of which is stationary (stationary phase) while the other (mobile phase) moves through it in a definite direction [8].

Since most of the pharmaceutical drugs are polar in nature they are easily separated by RP-HPLC method [9]. Mirabegron/2-(2-amino-1, 3thiazol-4-yl)-N-[4-[2-[[(2R)-2-hydroxy-2 phenyl ethyl] amino] ethyl] phenyl] acetamide is a beta-3 Adrenergic Agonist for beta- 3 adrenergic receptors. The literature survey reveals that only the methods based on development and validation of LC/TMSM for the determination of Mirabegron in heparinized human plasma and GC method for the determination of methanol, Diethyl Ether, Isopropyl alcohol and Toluene as residual solvents present in Mirabegron. The present work reveals that RP-HPLC method is an accurate rapid, specific, accuracy, precision and eliminates tedious extraction and isolation procedures [10-11].

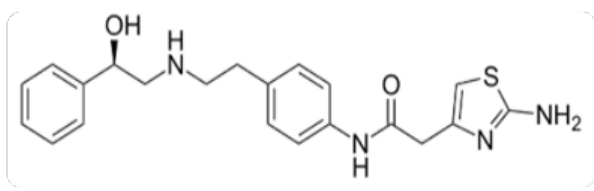

Structure of Mirabegron

\section{MATERIALS AND METHODS}

Instrumentation

Drug sample

Mirabegron working standard was procured from Natco laboratories, Hyderabad, India. Commercially available Mirabegron purchased from a local pharmacy. Acetonitrile HPLC Grade and Ortho phosphoric acid AR grade were obtained from Merck chemicals, Mumbai. Water was prepared by using Millipore Milli Q Plus water purification system. 
Table 1: List of equipment used in the method

\begin{tabular}{lll}
\hline S. No. & Name & Make/Model \\
\hline 1 & Analytical balance & Aicoset \\
2 & HPLC instrument & HPLC system (WATERS) \\
& Series & Alliance e2695 \\
& Software & EMPOWER-2 \\
3 & Columns & Acquity HSS T-3 C $18(100 \times 2.1 \mathrm{~mm}, 5 \mu \mathrm{m})$. \\
& & Acquity BEH C $18,(50 \mathrm{~mm} \times 2.1 \mathrm{~mm}, 5 \mu \mathrm{m})$ \\
4 & & Phenyl $(100 \mathrm{~mm} \times 2.1 \mathrm{~mm}, 5 \mu \mathrm{m})$ \\
5 & Detector & UV detector \\
6 & Sonicator & SONICA 2200MH \\
7 & pH meter & Metler Toledo \\
\hline
\end{tabular}

\section{Mobile phase}

\section{Preparation of phosphate buffer}

Weighed 7.0 grams of Potassium dihydrogen phosphate into a 1000 $\mathrm{ml}$ beaker, dissolve and diluted to $1000 \mathrm{ml}$ with milli pore water. Adjusted the $\mathrm{pH}$ to 4.0 with ortho phosphoric acid.

\section{Preparation of mobile phase}

Mixed a mixture of above buffer $400 \mathrm{ml}(40 \%)$ and $600 \mathrm{ml}$ of acetonitrile $(60 \%)$ and degas in an ultrasonic water bath for $5 \mathrm{~min}$. Filter through $0.45 \mu$ filter under vacuum filtration.

\section{Mirabegron standard solution preparation}

Accurately transferred $10 \mathrm{mg}$ of Mirabegron working standard into a $10 \mathrm{ml}$ volumetric flask and about $7 \mathrm{ml}$ of diluents added then sonicated to dissolve it completely and the volume was made up to the mark with the same solvent(Stock solution). Further pipetted 0.5 $\mathrm{ml}$ of the above stock solution into a $10 \mathrm{ml}$ volumetric flask and diluted up to the mark with diluent. Mix well and filter through 0.45 $\mu \mathrm{m}$ filter.

\section{Mirabegron sample solution preparation}

Accurately transferred the sample equivalent to $10 \mathrm{mg}$ of Mirabegron into a $10 \mathrm{ml}$ volumetric flask. About $7 \mathrm{ml}$ of diluent added and sonicated to dissolve it completely and the volume is made up to the mark with diluent. Mixed well and filtered through $0.45 \mu \mathrm{m}$ filter. Further pipetted $5 \mathrm{ml}$ of the above stock solution into a $50 \mathrm{ml}$ volumetric flask and diluted up to the mark with diluent. Mix well and filter through $0.45 \mu \mathrm{m}$ filter. Further pipetted $3 \mathrm{ml}$ of the above stock solution into a $10 \mathrm{ml}$ volumetric flask and dilute up to the mark with diluent. Mix well and filter through $0.45 \mu \mathrm{m}$ filter.

\section{Selection of mobile phase}

According to literature, Mirabegron is freely soluble acetonitrile and sparingly soluble in methanol. It was checked for different dilutions of acetonitrile and methanol for solubility of Mirabegron. Several proportions of buffer, and solvent were evaluated in order to obtain a suitable composition of the mobile phase. Buffers like sodium dihydrogen orthophosphate dipotassium hydrogen orthophosphate and disodium hydrogen orthophosphate did not yield desired results. Finally, a mixture of acetonitrile and phosphate buffer in the ratio of $(60: 40 \% \mathrm{v} / \mathrm{v})$ was chosen as a solvent for present work.

\section{Selection of wavelength: $\left(\lambda_{\max }\right)$}

An ideal wavelength is one that uses the good response for the drugs to be detected. In order to ascertain the optimum wavelength, Mirabegron in diluent was scanned on UV Visible spectrophotometer in the range of $200 \mathrm{~nm}$ to $300 \mathrm{~nm}$ against diluent as blank. From the UV Visible spectrophotometric results, the detection wavelength of $243 \mathrm{~nm}$ was selected because at this wavelength they show maximum absorbance. So the chromatographic condition was optimized at $230 \mathrm{~nm}$.

\section{Selection of initial chromatographic conditions}

Appropriate selection of chromatographic method depends upon the characteristic nature of the sample (ionic or ionisable or neutral), its molecular weight and solubility. The nature of Mirabegron is polar. Hence reverse phase chromatography is used. The reverse phase HPLC was selected for the initial chromatographic condition because of its simplicity and suitability. Different chromatographic conditions were experimented to achieve better efficiency of the chromatographic system. Parameters such as mobile phase composition, wavelength of detection, column, column temperature, $\mathrm{pH}$ of the mobile phase, and diluents were optimized. Choice of retention time, tailing, theoretical plates, and run time were the major tasks while developing the method. Acquity BEH $\mathrm{C}_{18}, 50 \mathrm{~mm} \times$ $2.1 \mathrm{~mm}, 1.7 \mu \mathrm{m}$ column used for the elution, but the broad peak obtained with a tailing factor of 2 . Experiment with Phenyl $(100 \mathrm{~mm}$ $\times 2.1 \mathrm{~mm}, 2 \mu \mathrm{m}$ ) column ended with inconsistent retention time and peak fronting. Waters Acquity HSS T- $3 \mathrm{C}_{18}(100 \mathrm{X} 2.1 \mathrm{~mm}, 1.7 \mu \mathrm{m})$ has produced a peak with adequate resolution and better efficiency.

Table 2: Optimized chromatographic conditions for mirabegron

\begin{tabular}{ll}
\hline Parameters & Method \\
\hline Stationary phase (column) & Waters Acquity HSS T-3 $\mathrm{C}_{18}(100 \times 2.1 \mathrm{~mm}, 1.7 \mu \mathrm{m})$ \\
Mobile Phase & Potassium dihydrogen phosphate: acetone in the ratio $(40: 60 \mathrm{v} / \mathrm{v})$ \\
$\mathrm{pH}$ & $6.0 \pm 0.02$ \\
Flow rate $(\mathrm{ml} / \mathrm{min})$ & 1.0 \\
Run time $($ minutes) & 6.0 \\
Column temperature $\left({ }^{\circ} \mathrm{C}\right)$ & Ambient \\
Volume of injection loop $(\mathrm{ml})$ & 20 \\
Detection wavelength $(\mathrm{nm})$ & 243 \\
Drugs RT (min) & 2.754 \\
\hline
\end{tabular}

\section{Chromatographic conditions}

\section{Method validation}

Based on International Conference on Harmonization (ICH) guidelines, the proposed method is validated with regard to system suitability, linearity, accuracy, precision, LOD, LOQ, robustness and sensitivity as follows.

\section{System suitability}

Standard solution of Mirabegron was prepared as per procedure and was injected six times into the HPLC system. The system suitability parameters were evaluated from standard Chromatograms obtained by calculating the \% RSD of retention times, tailing factor, theoretical plates and peak areas from six replicate injections. 
1. The $\%$ RSD for the retention times of principal peak from 6 replicate injections of each Standard solution should be not more than $2.0 \%$

2. The number of theoretical plates $(\mathrm{N})$ for the Mirabegron peak should be NLT 2000

3. The Tailing factor (T) for the Mirabegron peak should be NMT 2.0.

Assay

$$
\text { Assay } \%=\frac{\text { AT }}{\text { AS }} \times \frac{\text { WS }}{\text { DS }} \times \frac{\text { DT }}{\text { WT }} \times \frac{\text { P }}{100} \times \frac{\text { AVG Wt }}{\text { LableClaim }} \times 100
$$

Where: AT = Peak Area of obtained with test preparation

AS $=$ Peak Area of obtained with standard preparation.

WS $=$ Weight of working standard taken in $\mathrm{mg}$

WT $=$ Weight of sample taken in $\mathrm{mg}$
DS $=$ Dilution of Standard solution

DT = Dilution of sample solution

$\mathrm{P}=$ Percentage purity of working standard

\section{RESULTS AND DISCUSSION}

\section{System suitability}

Tailing factor obtained from the standard injection is 1.6 Theoretical Plates obtained from the standard injection is 2736.7 . The results proved that the optimized HPLC method fulfills these requirements within the ICH accepted limits indicated in the 'Experimental' section

\section{Precision}

The \% RSD of Mirabegron assay during the method precision was found to be $0.4 \%$, indicating the good precision of the method. The results are summarized in table 3 . And the corresponding chromatograms were illustrated in fig. from fig. 1-5.

Table 3: Results of precision

\begin{tabular}{ll}
\hline Injection & Area \\
\hline Injection-1 & 4796667 \\
Injection-2 & 4712916 \\
Injection-3 & 4721422 \\
Injection-4 & 4771493 \\
Injection-5 & 4750737 \\
Average & 4750647 \\
Standard deviation & 34749.6 \\
\% RSD & $0.4 \%$ \\
\hline
\end{tabular}

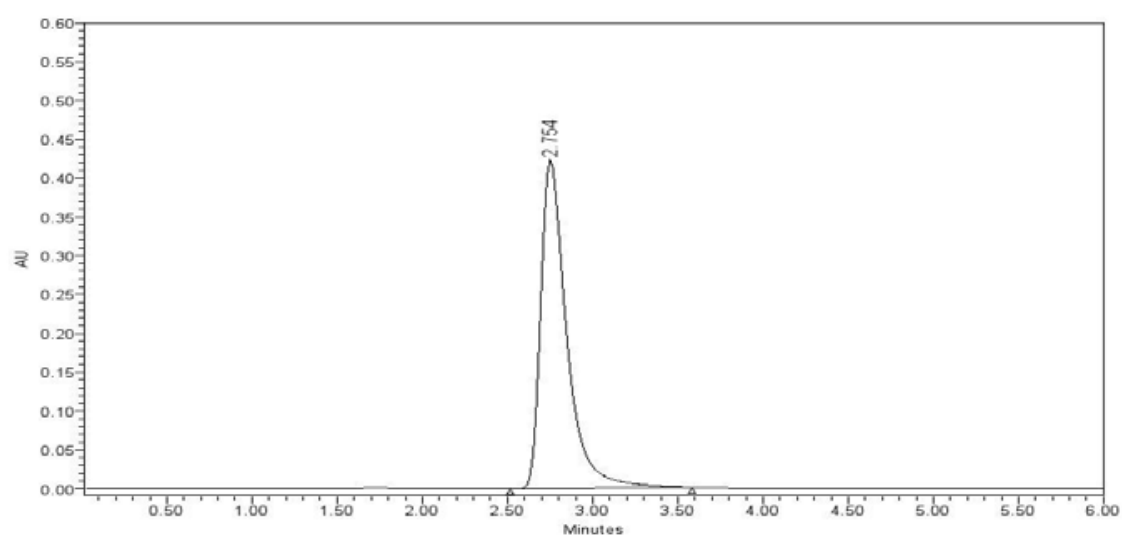

Fig. 1: Chromatogram for precision injection-1

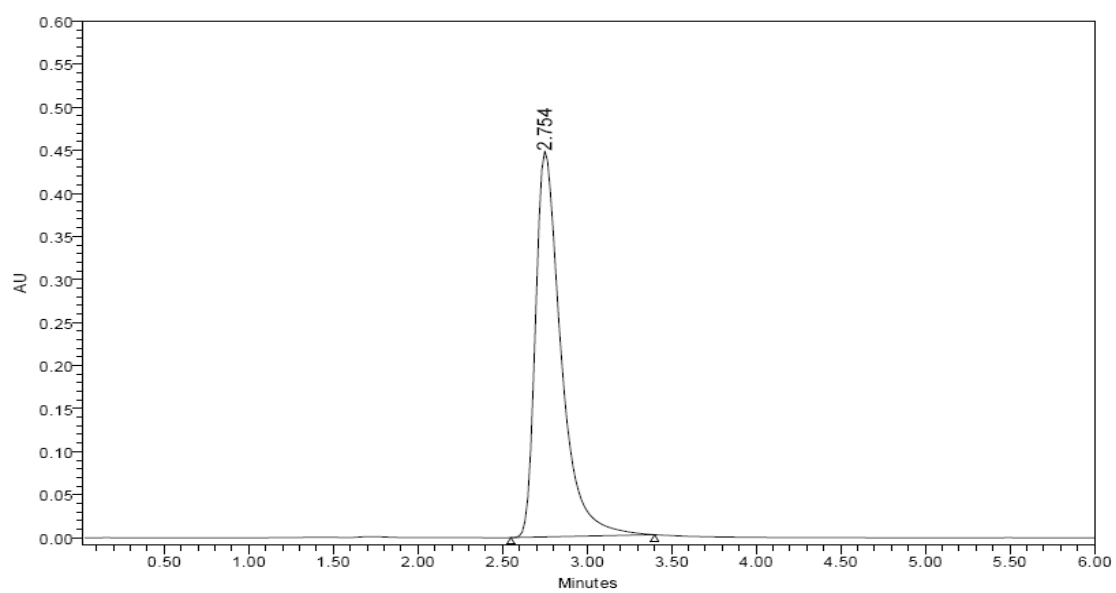

Fig. 2: Chromatogram for precision injection-2 


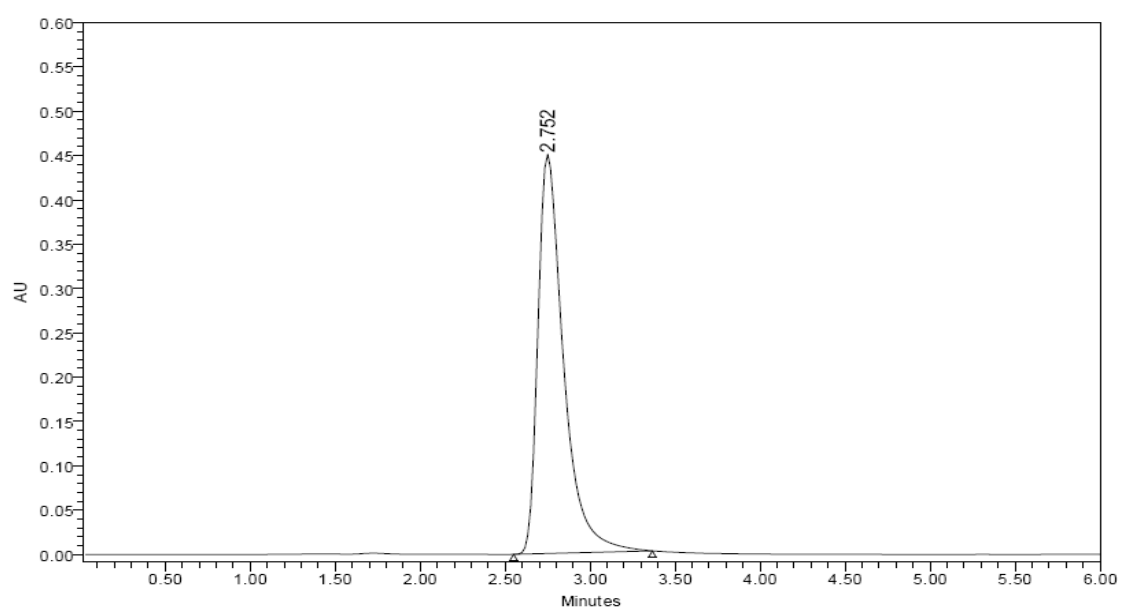

Fig. 3: Chromatogram for precision injection-3

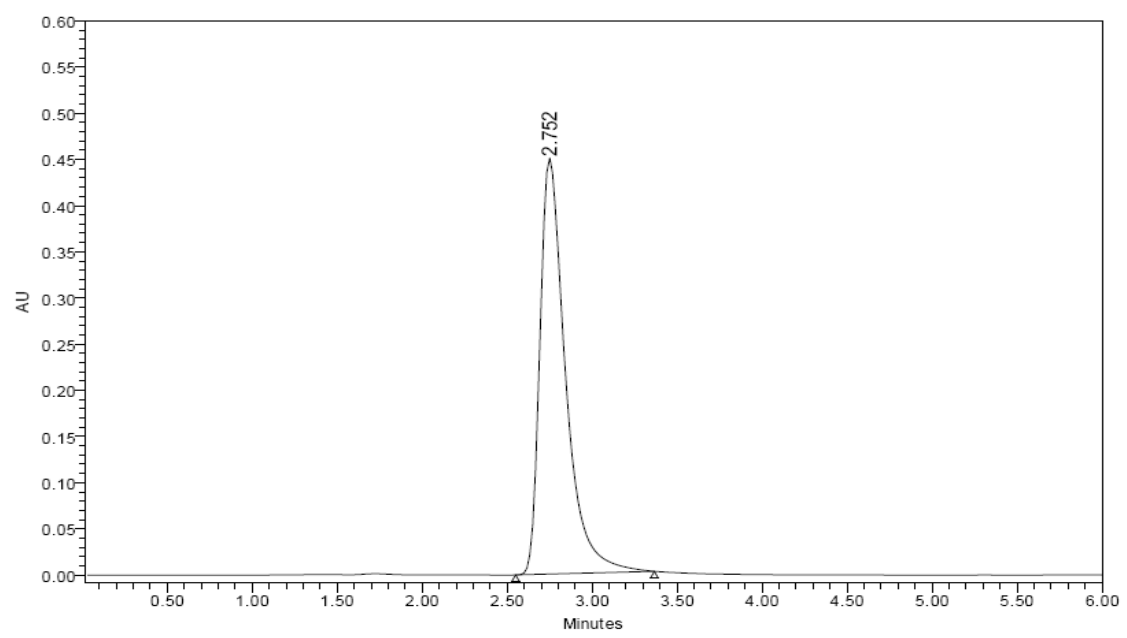

Fig. 4: Chromatogram for precision injection-4

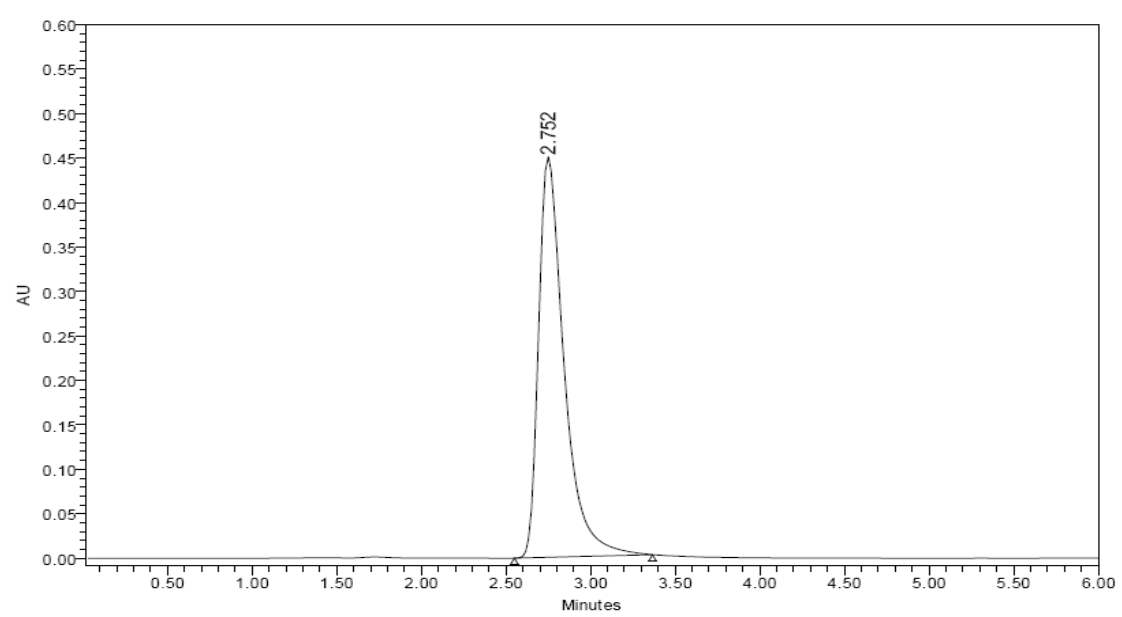

Fig. 5: Chromatogram for precision injection-5

\section{Intermediate precision}

The \% RSD of Mirabegron assay during the intermediate precision was found to be $0.08 \%$, the value is well within the generally acceptable limits. The results are summarized in table 4 and the chromatograms were depicted in fig. from fig. 6 to 10 .

\section{Accuracy}

The percentage recovery of Mirabegron samples ranged from $98.8 \%$ to $101.4 \%$ and the mean recovery is $99.8 \%$, showing the good accuracy of the method. The result is shown in table 5 . The chromatograms were shown in fig. from fig. 11-19. 
Table 4: Results of intermediate precision

\begin{tabular}{ll}
\hline Injection & Area \\
\hline Injection-1 & 4696666 \\
Injection-2 & 4616416 \\
Injection-3 & 4621626 \\
Injection-4 & 4671793 \\
Injection-5 & 4656697 \\
Average & 4652640 \\
Standard deviation & 33895.5 \\
\%RSD & $0.08 \%$ \\
\hline
\end{tabular}

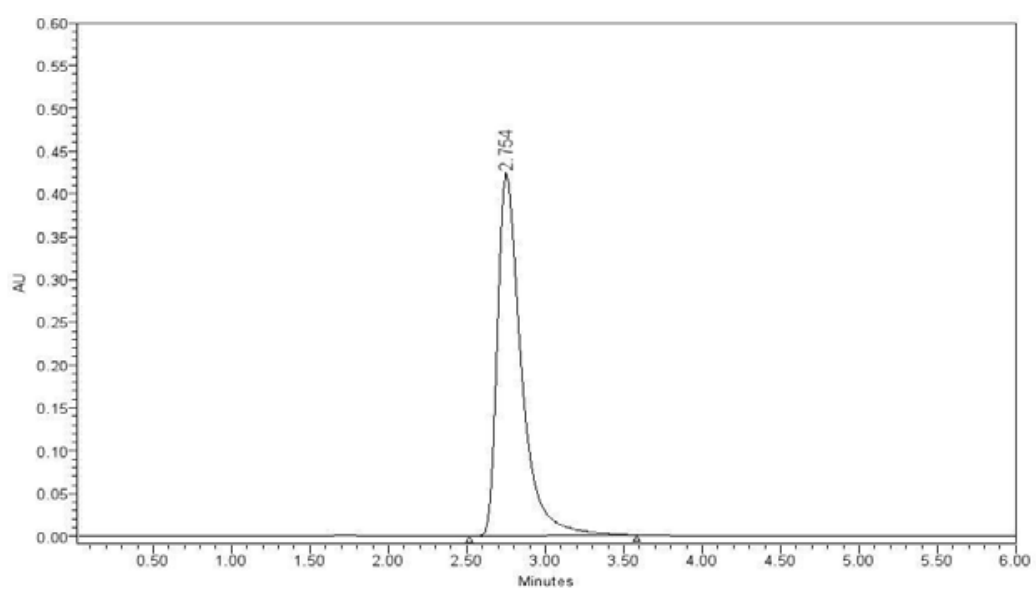

Fig. 6: Chromatogram for intermediate precision injection-1

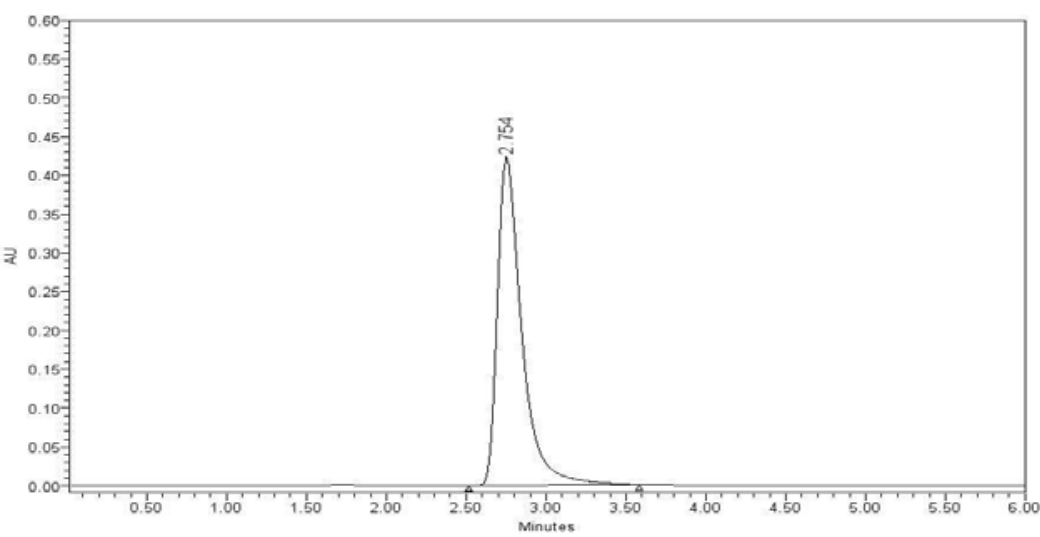

Fig. 7: Chromatogram for intermediate precision injection-2

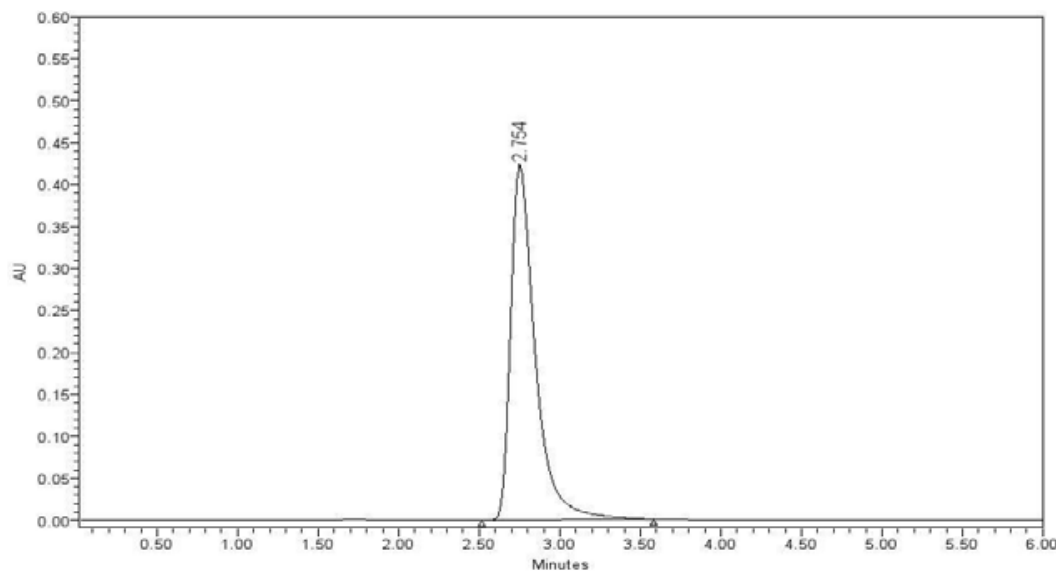

Fig. 8: Chromatogram for intermediate precision injection-3 


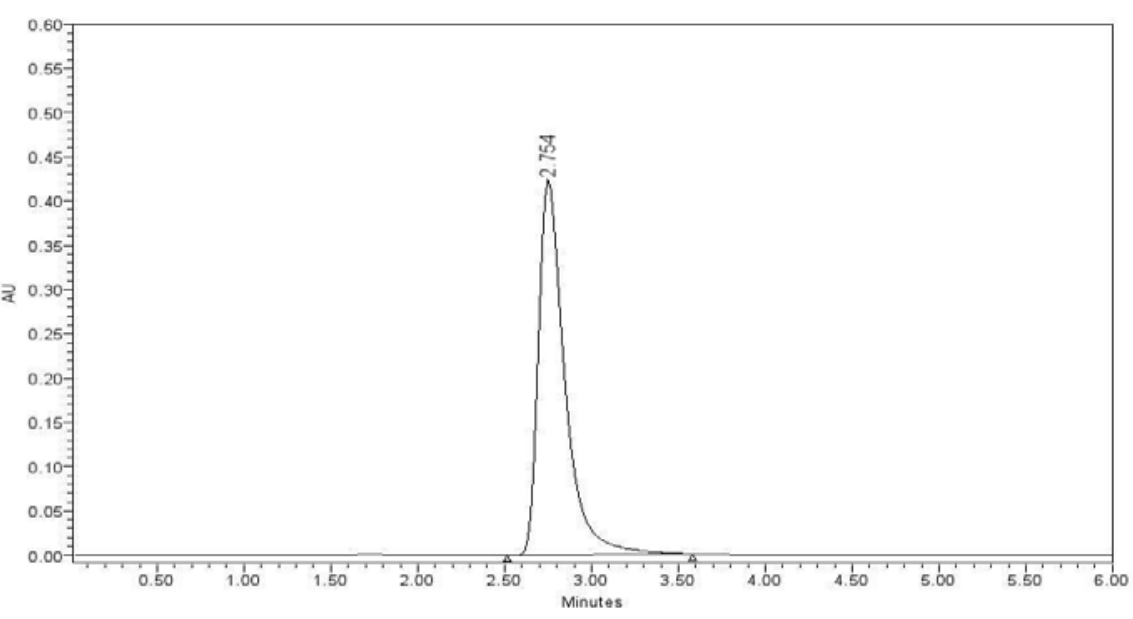

Fig. 9: Chromatogram for intermediate precision injection-4

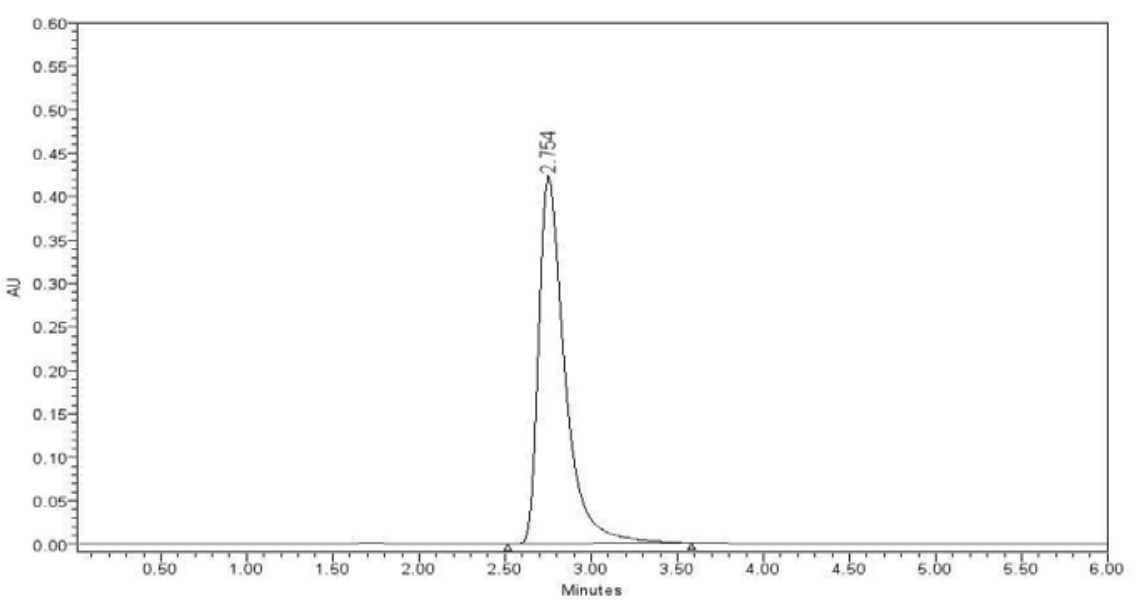

Fig. 10: Chromatogram for intermediate precision injection-5

Table 5: Results of accuracy

\begin{tabular}{lllll}
\hline $\begin{array}{l}\text { \% concentration } \\
\text { (at specification level) }\end{array}$ & $\begin{array}{l}\text { Mean peak } \\
\text { area (n=3) }\end{array}$ & $\begin{array}{l}\text { Amount added } \\
\text { (mg) }\end{array}$ & $\begin{array}{l}\text { Amount found } \\
\text { (mg) }\end{array}$ & $\begin{array}{l}\text { Average } \\
\text { \% recovery }\end{array}$ \\
\hline $50 \%$ & 4838809 & 5.0 & 5.07 & $101.4 \%$ \\
$100 \%$ & 9462459 & 10.0 & 9.91 & $99.1 \%$ \\
$150 \%$ & 14149612 & 15.0 & 14.8 & $98.8 \%$ \\
\hline
\end{tabular}

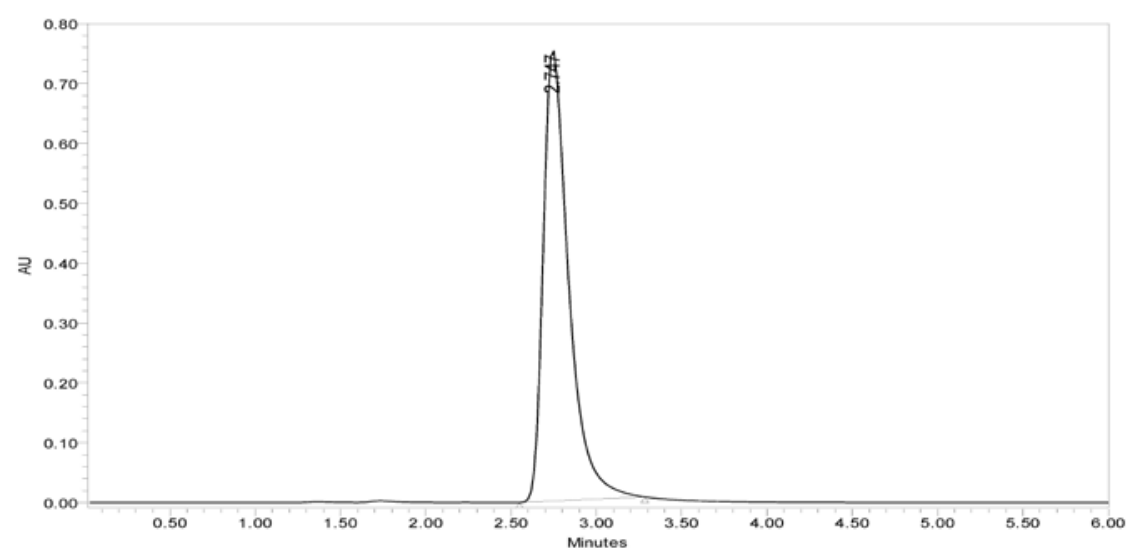

Fig. 11: Chromatogram for accuracy $50 \%$ injection-1 


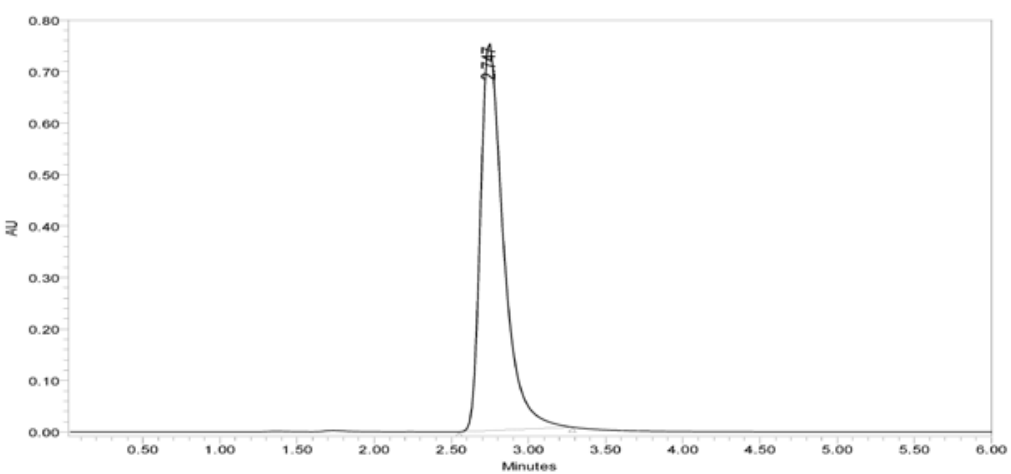

Fig. 12: Chromatogram for accuracy $50 \%$ injection-2

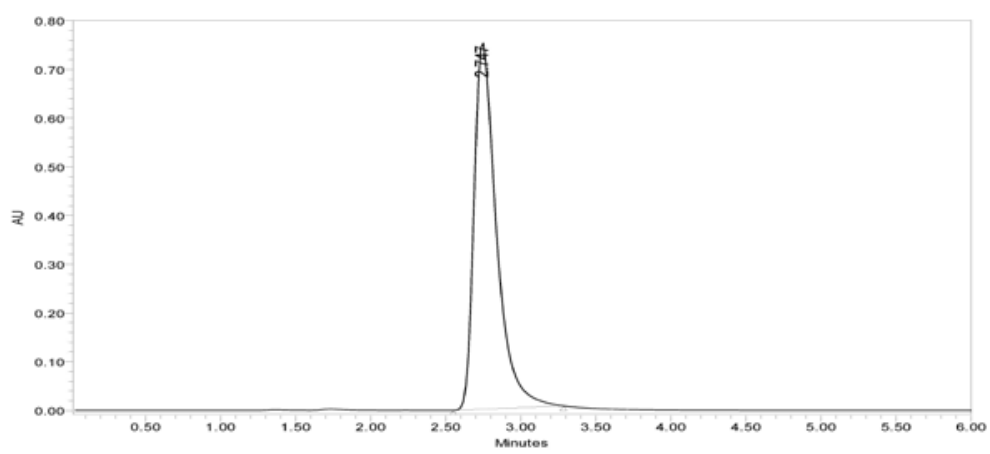

Fig. 13: Chromatogram for accuracy $50 \%$ injection-3

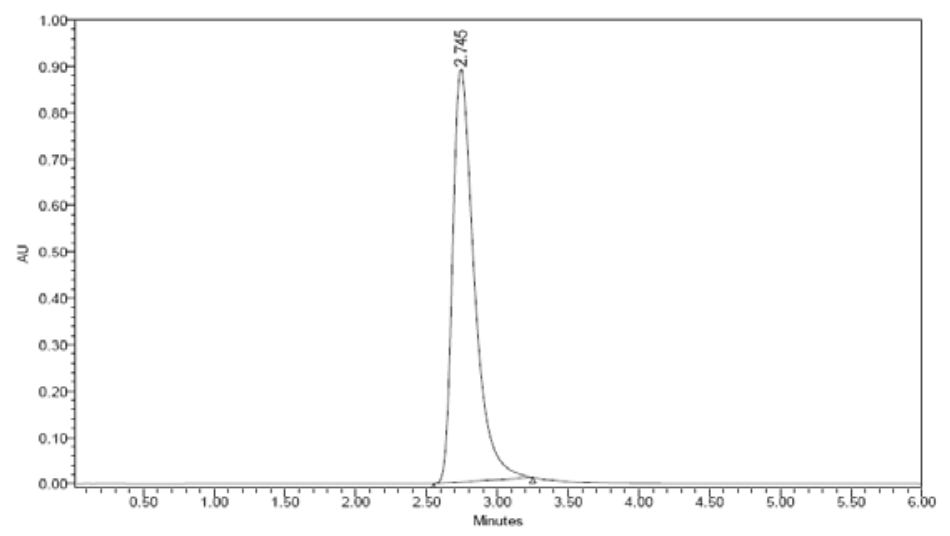

Fig. 14: Chromatogram for accuracy $100 \%$ injection-1

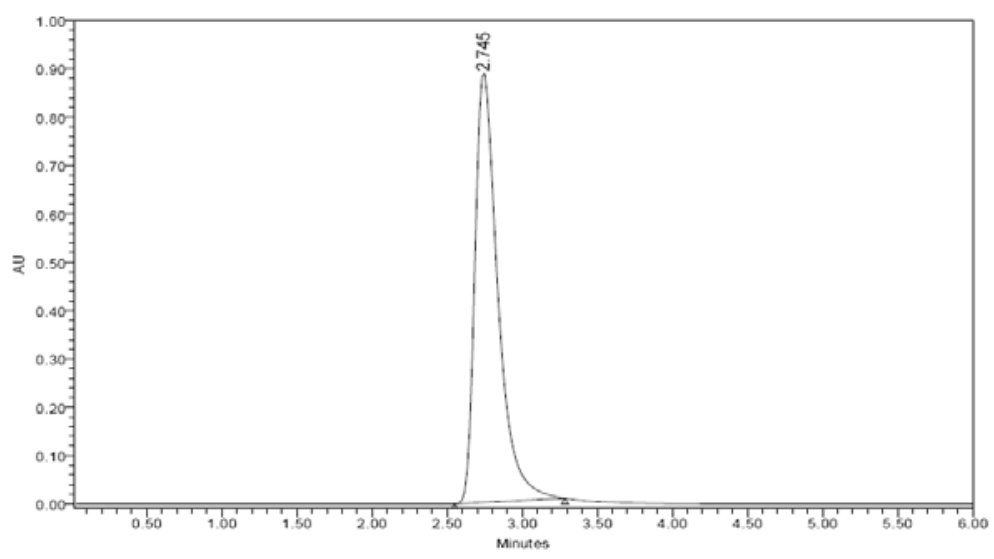

Fig. 15: Chromatogram for accuracy $100 \%$ injection-2 


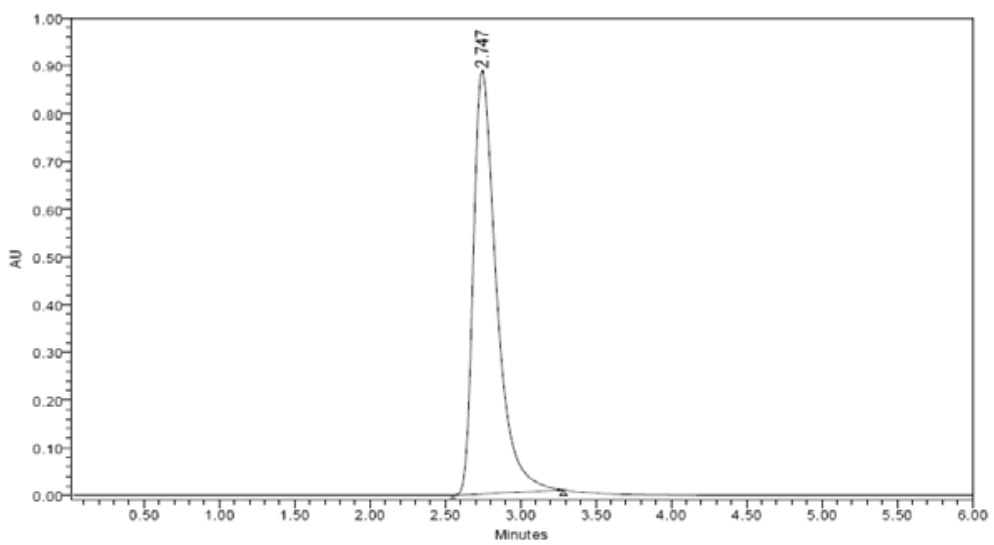

Fig. 16: Chromatogram for accuracy $100 \%$ injection-3

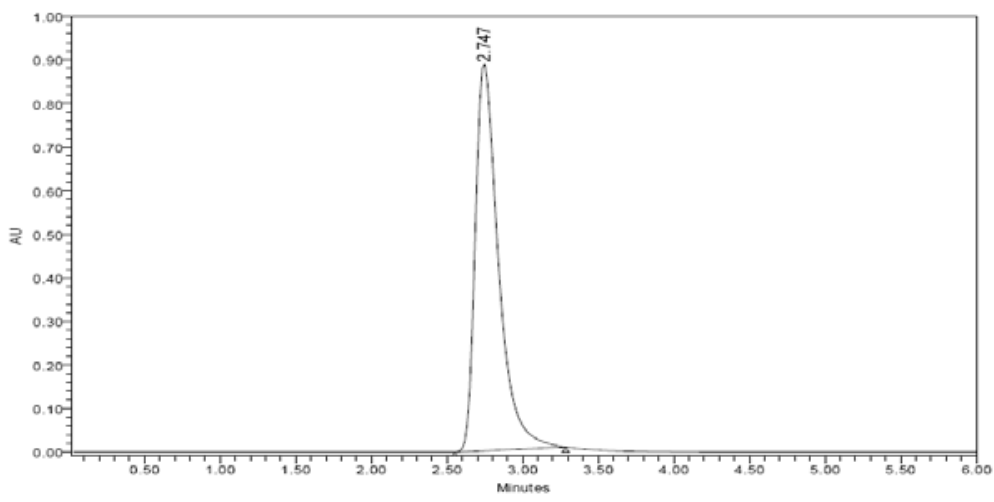

Fig. 17: Chromatogram for accuracy $150 \%$ injection-1

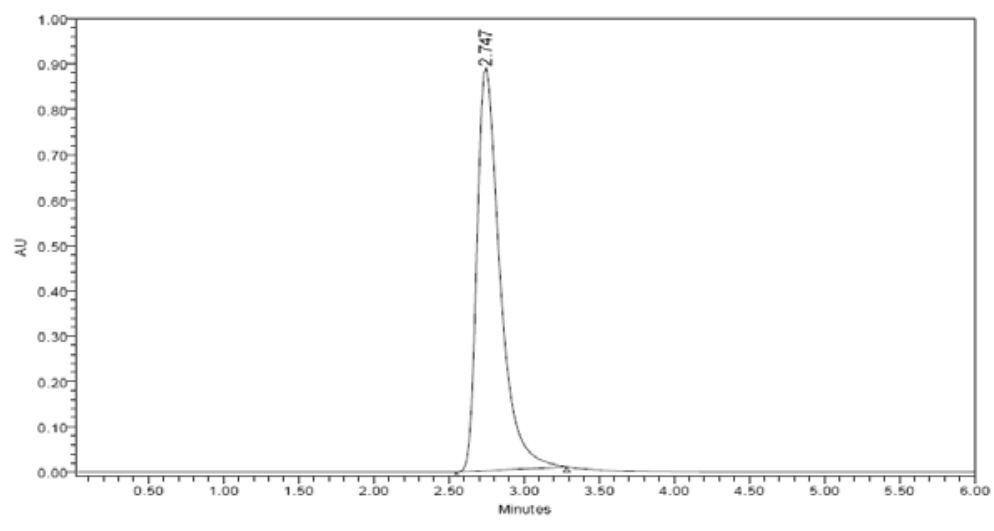

Fig. 18: Chromatogram for accuracy $150 \%$ injection-2

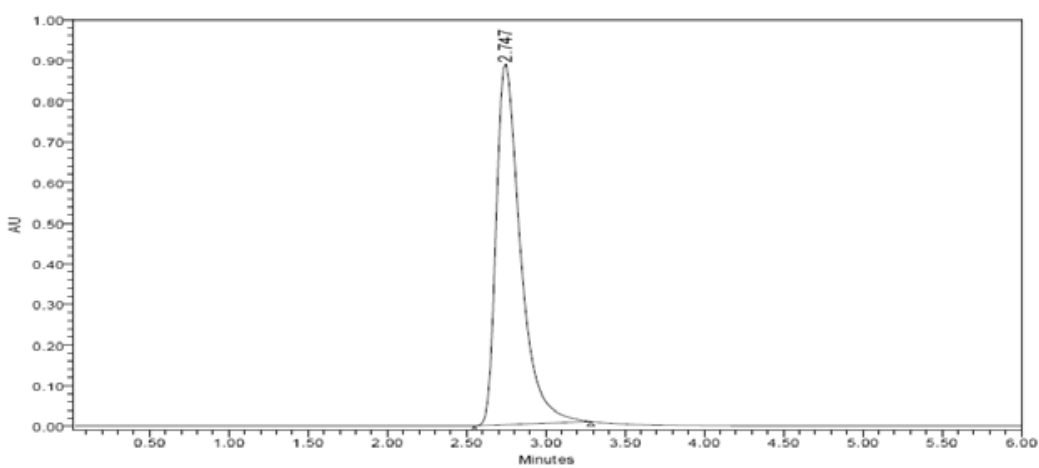

Fig. 19: Chromatogram for accuracy $150 \%$ injection-3 


\section{Linearity}

The linearity of the calibration plot for the method was obtained over the calibration ranges tested, i.e., $30-70 \mu \mathrm{g} / \mathrm{ml}$ for three times, and the correlation coefficient obtained was 0.999 thus indicating an excellent correlation between peak areas and concentrations of the analyte. The results were summarized in table 6 and the linearity curve for Mirabegron was illustrated in fig. 20. The corresponding chromatograms were illustrated in fig. from fig. 2125 .

Table 6: Linearity results

\begin{tabular}{lll}
\hline S. No. & Concentration & Area \\
\hline 1 & $30 \mu \mathrm{g} / \mathrm{ml}$ & 2939828 \\
2 & $40 \mu \mathrm{g} / \mathrm{ml}$ & 3978576 \\
3 & $50 \mu \mathrm{g} / \mathrm{ml}$ & 5125552 \\
4 & $60 \mu \mathrm{g} / \mathrm{ml}$ & 6168913 \\
5 & $70 \mu \mathrm{g} / \mathrm{ml}$ & 7047599 \\
Correlation Coefficient & 0.999 & \\
\hline
\end{tabular}

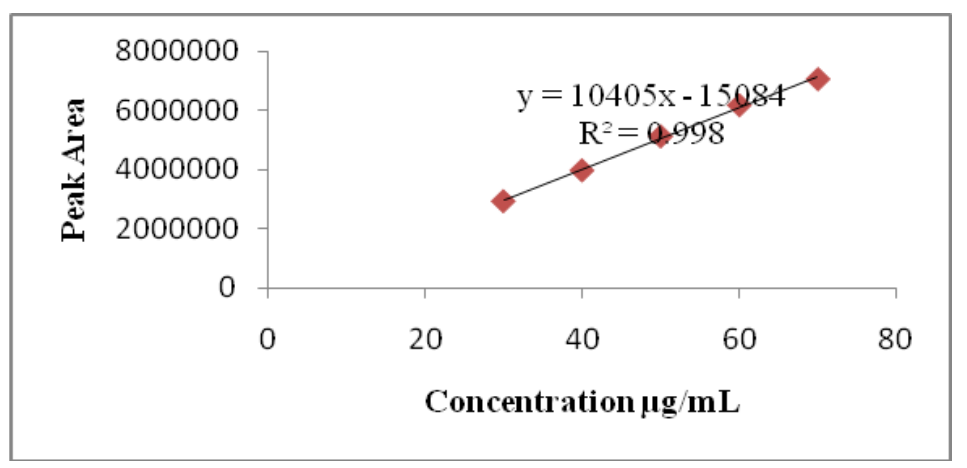

Fig. 20: Linearity curve for mirabegron

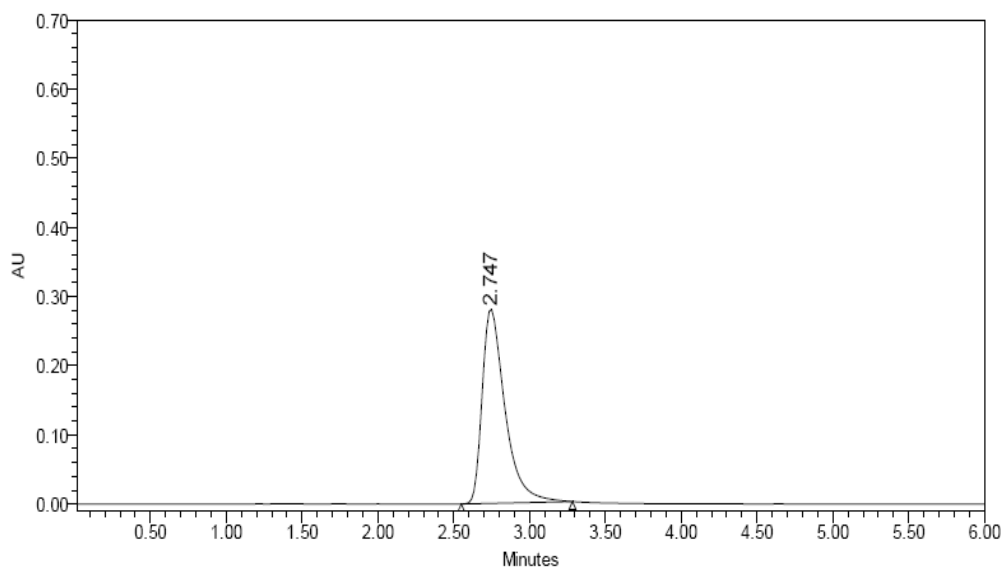

Fig. 21: Chromatogram for linearity injection-1

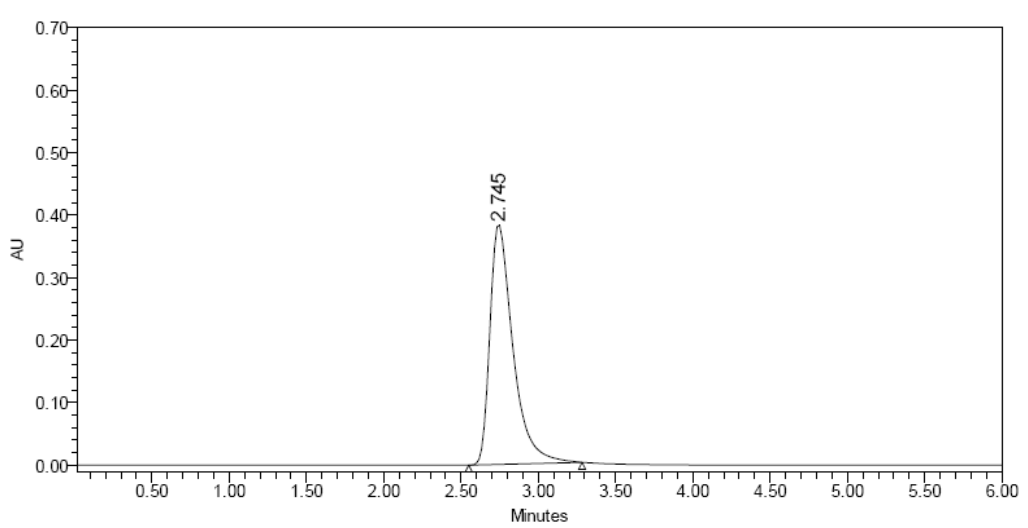

Fig. 22: Chromatogram for linearity injection-2 


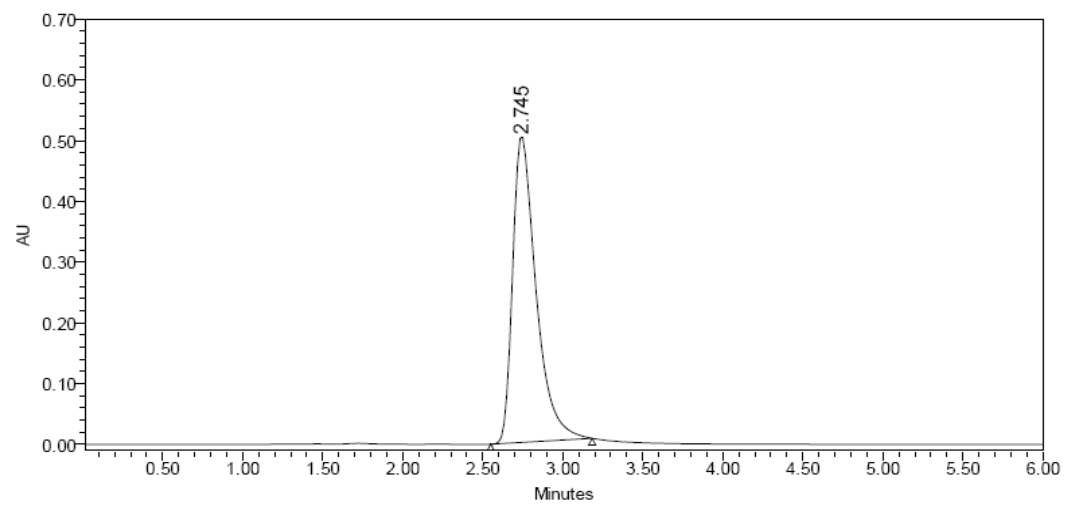

Fig. 23: Chromatogram for linearity injection-3

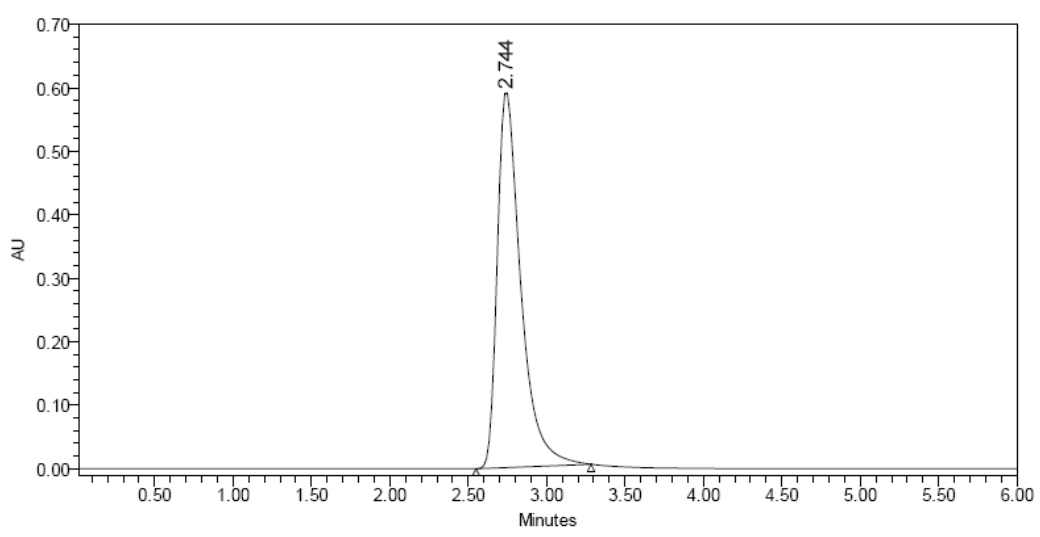

Fig. 24: Chromatogram for linearity injection-4

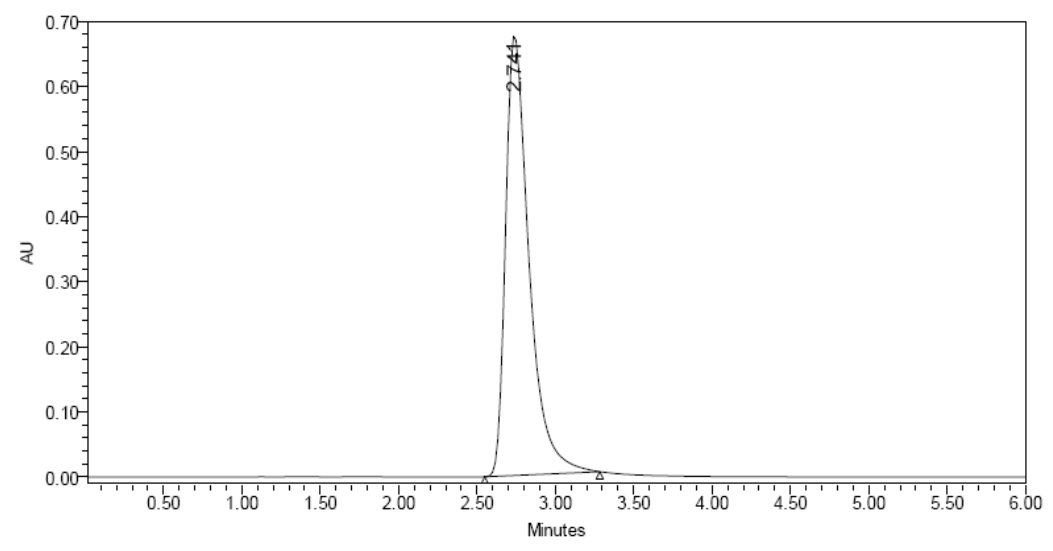

Fig. 25: Chromatogram for linearity injection-5

Table 7: Results of robustness

\begin{tabular}{lll}
\hline Chromatographic changes & USP plate count & USP tailing \\
\hline Flow rate(ml/min) & & 1.7 \\
0.6 & 2679.7 & 1.6 \\
$0.8^{*}$ & 2736.7 & 1.7 \\
1.0 & 2597.1 & 1.5 \\
Change in organic composition in the mobile phase & & 1.6 \\
$10 \%$ less & 2311.0 & 1.5 \\
$60: 40$ (Buffer: methanol) & 2736.7 & 1.5 \\
$10 \%$ more & 2218.0 & 1.6 \\
UV wavelength (nm) & & 1.54 \\
226 & 2617.0 & 2986.7 \\
$228^{*}$ & 2529.0 & \\
230 & & \\
\hline
\end{tabular}

*optimized parameters 


\section{Robustness}

In all the deliberately varied chromatographic conditions in the concentration range for the evaluation of robustness is $10-50 \mu \mathrm{g} / \mathrm{ml}$, $(n=3)$. It can be concluded that the variation in flow rate and the variation in $10 \%$ Organic composition do not affect the method significantly. Hence it indicates that the method is robust even by a change in the flow rate $\pm 10 \%$ and change in the Mobile phase $\pm 10 \%$. The results are summarized in table 7.

\section{Limits of detection (LOD) and quantification (LOQ)}

LOD and LOQ for Mirabegron were $0.01 \mu \mathrm{g} / \mathrm{ml}$ and $0.05 \mu \mathrm{g} / \mathrm{ml}$, respectively. Since the LOQ and LOD values of Mirabegron are achieved at a very low level, this method can be suitable for cleaning validation in the pharmaceutical industry. The corresponding chromatograms were given in fig. 26-27 for LOD and LOQ respectively.

Application of the developed method to commercial mirabegron tablets

When the developed method was used to analyze a commercial brand of Mirabegron tablet formulation, the mean recovery of triplicates was $99.8 \%$ with \% RSD of 0.09 . The \% recovery value indicates non-interference from the excipients present in the dosage form. The chromatograms were depicted in fig. from fig. 28-30.

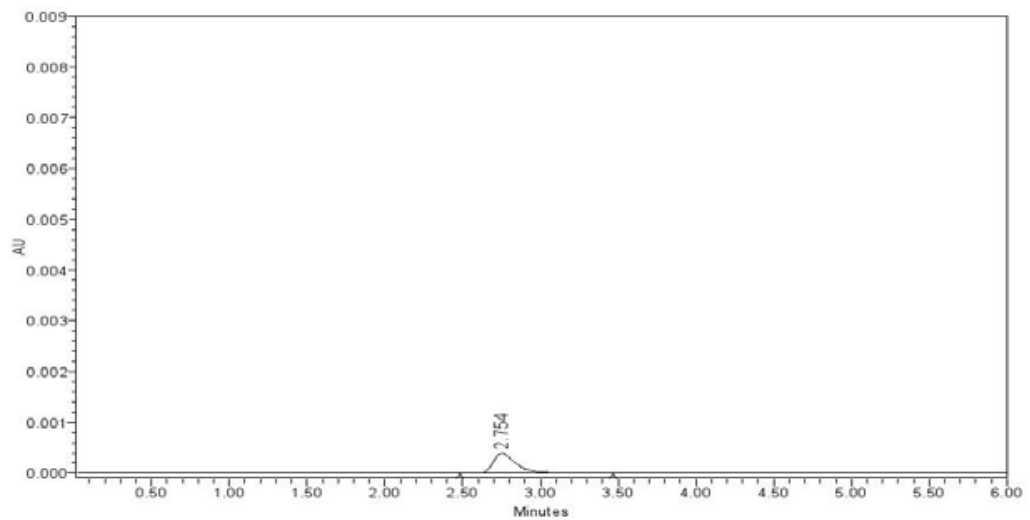

Fig. 26: Chromatogram for LOD

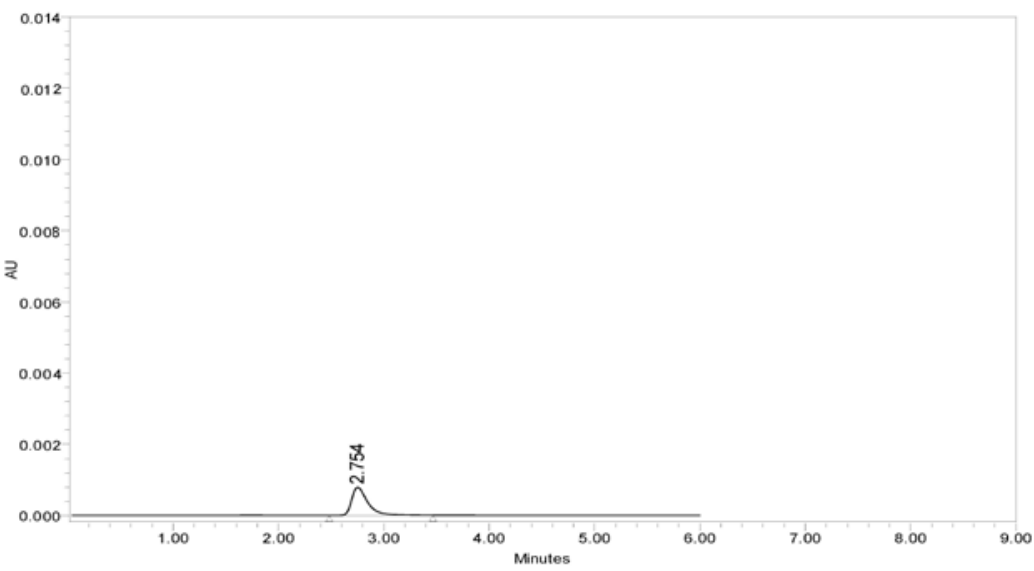

Fig. 27: Chromatogram for LOQ

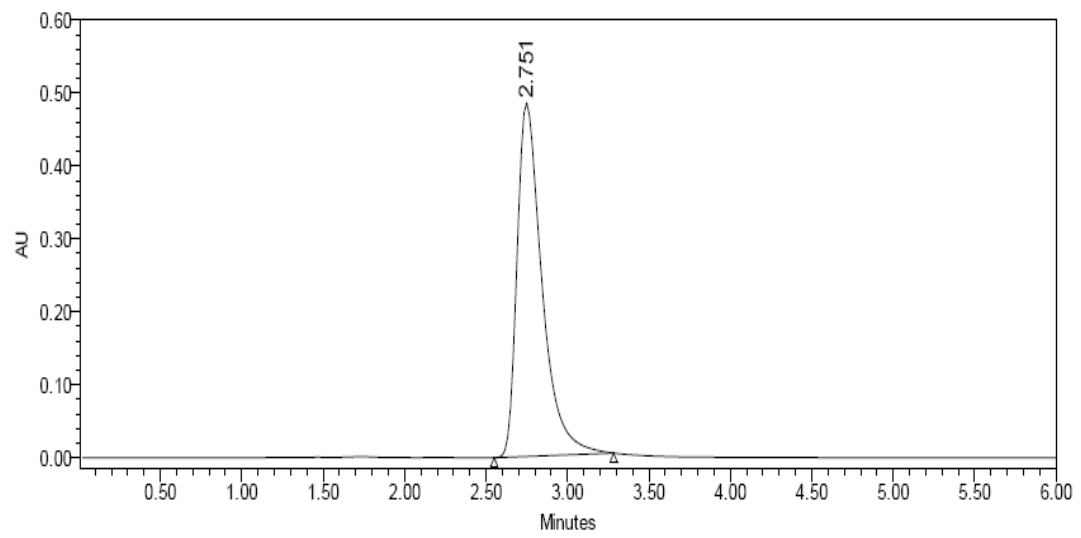

Fig. 28: Chromatogram for sample injection-1 


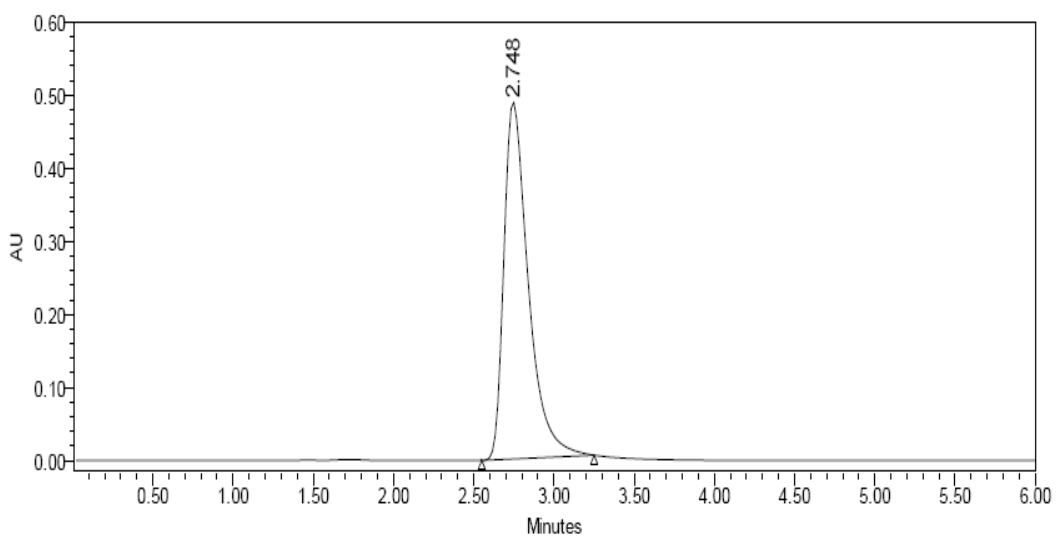

Fig. 29: Chromatogram for sample injection-2

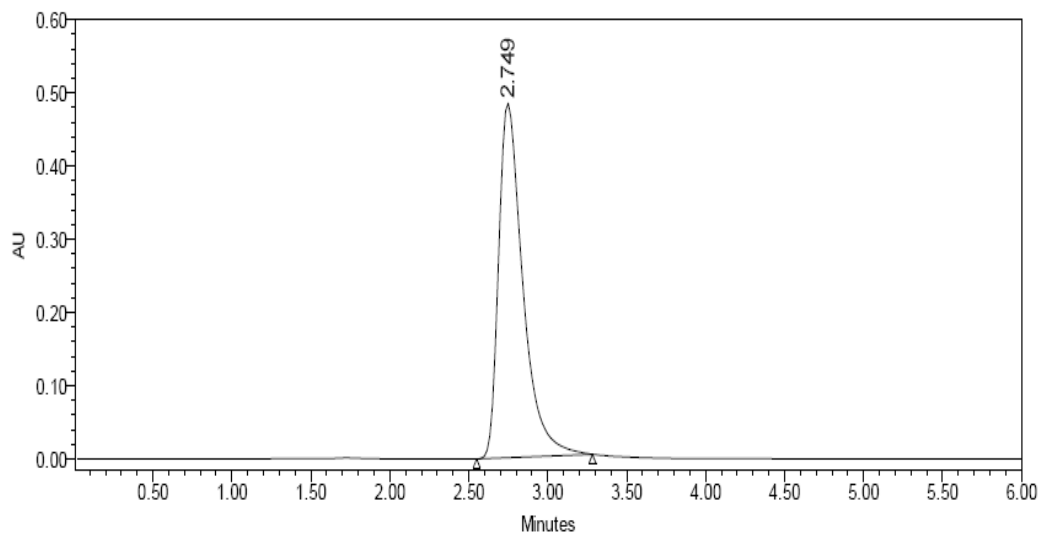

Fig. 30: Chromatogram for sample injection-3

\section{Assay}

Weight of 5 tablets: 0.8285 grams

Average Weight: 0.1971 grams

$$
\frac{5165251}{5168473} * \frac{10}{10} * \frac{0.5}{10} * \frac{10}{197.13} * \frac{10}{0.5} * \frac{99.9}{100} * \frac{197.13}{10} * 100=99.8 \%
$$

\section{CONCLUSION}

The new, isocratic RP-HPLC method proved to be simple, linear, precise, accurate, robust, rugged and rapid. The developed method was capable of giving faster elution, maintaining good separation more than that achieved with conventional HPLC. The short retention time of $2.754 \mathrm{~min}$ allows the analysis of a large number of samples in a short period of time and is, therefore, more costeffective for routine analysis in the pharmaceutical industries. Hence it is suitable for rapid and accurate quality control of Mirabegron in tablet formulations.

\section{ACKNOWLEDGEMENT}

The authors are thankful to the Management of SVS Group of Institutions, Warangal, for providing laboratory facilities and financial support.

\section{CONFLICT OF INTERESTS}

Declare none

\section{REFERENCES}

1. Gell PGH, Coombs RRA. Clinical aspects of immunology. London: Blackwell; 1963;12:225-45.
2. Skoog DA, West DM, Holes JF. Fundamentals of analytical chemistry. 7th ed. Harcourt: College Publishers; 2001. p. 1-5.

3. Sethi PD. HPLC quantitative analysis of drugs in pharmaceutical formulations. 3rd Ed. New Delhi: CBS publisher and distributors; 2001. p. 53-62.

4. Kennedy JH. Analytical Chemistry: Principles. 2nd Ed. New York: Saunders College publishing; 1990. p. 3-20.

5. Lee MS, Kerns EH. Mass Spectrum. Rev 1999;18:187

6. Lee MS. LC-MS applications in drug development. New York, USA: John Wiley and Sons; 2002

7. Gennaro AR, Remington: The Science and Practice of Pharmacy. 20th ed. Lippincott Williams and Wilkins; 2000. p. 587-610.

8. Kazakevich Y, LoBrutto R. HPLC for Pharmaceutical Scientists. New York, USA: A John Wiley and sons, Inc; 2007. p. 5.

9. Chusena Narasimharaju Bhimanadhuni, Devala Rao Garikapati. RP-HPLC method for the determination of mirabegron in pharmaceutical dosage. Am J PharmTech Res 2012;2:564-71.

10. Raymond Van Teijingen, John Meijer, Shin Takusagawa, Marce Van Geldren, Cas Van Den Beld, Takashi Usui. Development and validation of LC-MS/MS methods for the determination of Mirabegron and its metabolites in human plasma and their application to a clinical pharmacokinetic study. J Chromatography B 2012;887-888:102-11.

11. Chusena Narasimharaju Bhimanadhuni, Devala Rao Garikapati. Development and validation of gas chromatography method for the determination of residual solvents in Mirabegron. Pharm Chem 2013;5:55-60.

\section{How to cite this article}

- $\quad$ B Mounika, L Srikanth, A Venkatesha. Determination and validation of a RP-HPLC method for the estimation of mirabegron in tablet dosage form. Int J Curr Pharm Res 2017;9(5):140-151. 